\title{
Apicoectomy of Perforated Root Canal Using Bioceramic Cement and Photodynamic Therapy
}

\author{
Amjad Abu Hasna $\mathbb{D}^{1},{ }^{1}$ Daiane Pereira Santos $\mathbb{D D}^{2},{ }^{2}$ Tania Regina Gavlik de Oliveira $\mathbb{D}^{2}{ }^{2}$ \\ Alana Barbosa Alves Pinto $\mathbb{D},{ }^{3}$ César Rogerio Pucci $\mathbb{D}^{4},{ }^{4}$ and José Luiz Lage-Marques $\mathbb{D}^{5}$ \\ ${ }^{1}$ Department of Restorative Dentistry, Endodontics Division, Institute of Science and Technology, \\ São Paulo State University-UNESP, São José Dos Campos, SP, Brazil \\ ${ }^{2}$ Faculty of Dentistry, São Leopolodo Mandic, São Paulo, SP, Brazil \\ ${ }^{3}$ Department of Dental Materials and Prosthodontics, Institute of Science and Technology, São Paulo State University-UNESP, \\ São José Dos Campos, SP, Brazil \\ ${ }^{4}$ Department of Restorative Dentistry, Institute of Science and Technology, São Paulo State University-UNESP, \\ São José Dos Campos, SP, Brazil \\ ${ }^{5}$ Department of Restorative Dentistry, School of Dentistry, University of São Paulo, São Paulo, SP, Brazil
}

Correspondence should be addressed to César Rogerio Pucci; cesar@fosjc.unesp.br

Received 24 October 2020; Revised 22 November 2020; Accepted 2 December 2020; Published 10 December 2020

Academic Editor: Luca Testarelli

Copyright (c) 2020 Amjad Abu Hasna et al. This is an open access article distributed under the Creative Commons Attribution License, which permits unrestricted use, distribution, and reproduction in any medium, provided the original work is properly cited.

\begin{abstract}
Root perforation is a common endodontic accident. Its management depends mainly on root canal disinfection and sealing the perforation area by preventing any communication with the periodontium to prevent recontamination. A patient was referred to treat root perforation due to a previous treatment of tooth \#22. The diagnosis was symptomatic periapical periodontitis, and the treatment plan was to retreat the root canal of \#22 and make a surgical intervention (apicoectomy) associated with antimicrobial photodynamic therapy as a complementary technique. Five mineral oxides $(5 \mathrm{MO})$ cement was used as a root-end filling material. The procedures were performed in two sessions and controlled in two visits (after 30 days and 12 months). A bone neoformation was observed at the periapical area of tooth \#22. $5 \mathrm{MO}$ bioceramic cement was effective in inducing the repair of the periapical lesion and had the ability to seal the exposed periapical area of the tooth. Its success depended mainly on root canal and surgical site disinfection.
\end{abstract}

\section{Introduction}

The symptomatic periapical periodontitis is an endodontic disease of the necrosed pulp and its management depends mainly on root canal disinfection [1] in which the manual/ automated instruments remove the microorganisms mechanically and the auxiliary chemical substances act chemically [2-4]. However, in some cases, additional complementary techniques are indicated to provide more favorable decontamination using photodynamic therapy (PDT) $[5,6]$ and passive ultrasonic irrigation (PUI) $[7,8]$. As well, the endodontic irrigants play a principal role in reducing torsional and fatigue resistance during instrumentation [9].

During the endodontic treatment [10], some complications like root chamber or root canal perforation may occur because of operative procedural accidents [11] which may be related to lack of experience of the professional [12] or pathological factors [13]. Endodontic perforation results in communicating the root canal system with the periodontium that may lead to tooth loss unless good management is carried out [14].

Endodontic (paraendodontic) surgery was started in the last century as the last alternative of endodontic intervention [15]. It results in satisfactory treatment outcomes and lesion regression [16] without clinical signs and symptoms of inflammation [17].

The bioceramic cements played a major effect on the success of endodontic surgery, since the introduction of mineral trioxide aggregate (MTA) [14, 18-20], Biodentine [21], and lastly the five mineral oxides (5MO) $[16,22]$. 


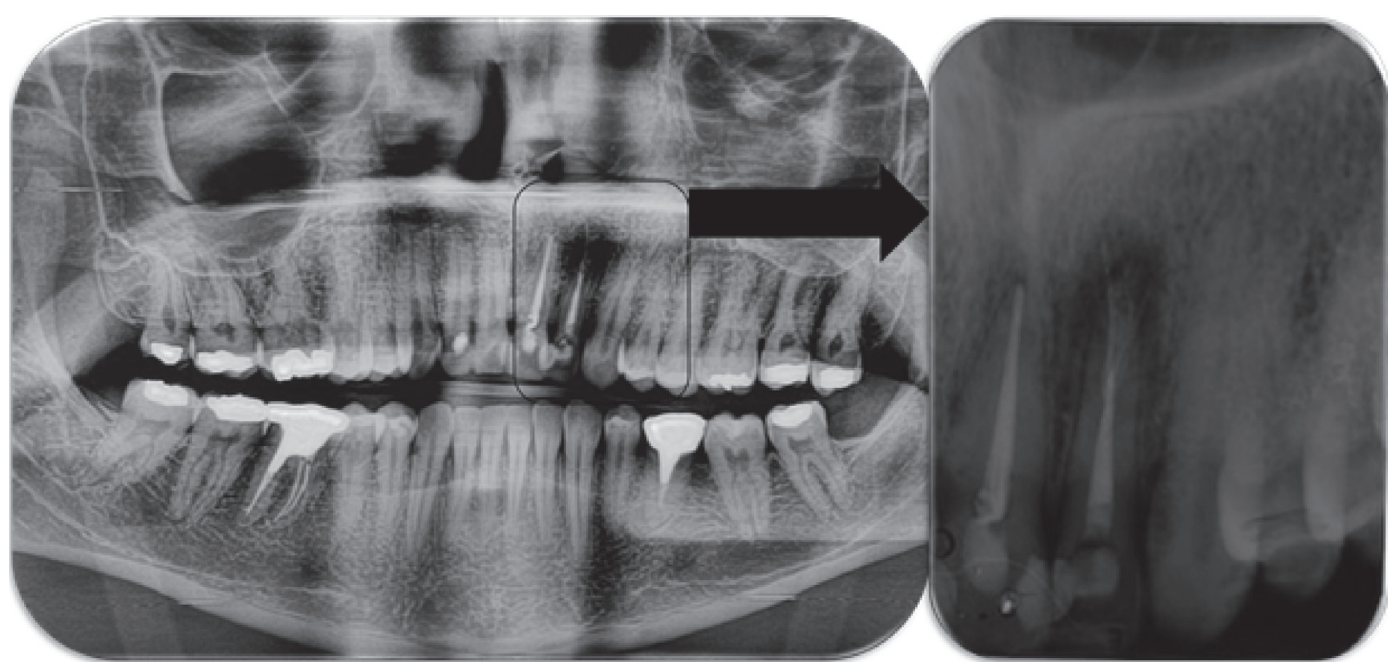

FIgURE 1: Initial panoramic and periapical radiography of the periapical lesion of tooth \#22.

The photodynamic therapy is a complementary technique, which aids in additional disinfection using a light source like laser or light-emitting diode (LED) acting over a photosensitizer and thus liberating reactive oxygen specimens that disinfect some facultative microorganisms [23] and resulting in more accelerated tissue repair $[5,24,25]$.

The aim of this case report was to evaluate the effect of $5 \mathrm{MO}$ bioceramic cement on periapical lesion repair and its ability to seal the exposed periapical area of the tooth.

\section{Case Report}

2.1. Case Presentation and Patient Information. A Brazilian white 31-year-old male was indicated to treat the left upper lateral incisor \#22. The patient stated a "bad experience" with the root canal treatment and a "continuous discomfort". The patient's clinical history did not present relevant findings.

The clinical examination revealed a positive response to percussion and digital palpation in the periapical region of \#22 with no fistula. The intraoral examination did not show any caries or color alteration related to the respected tooth. The depth of its gingival pocket varied between 1 and $3 \mathrm{~mm}$ with various exploring locations and grade I mobility. Teeth 21-23 were tested by the pulp vitality test (the cold test) performed by refrigerant gas (Endo Ice, Maquira Dental products industry LTDA, Brazil) and relative isolation using cotton rolls and a dental saliva ejector. Teeth 21 and 23 presented positive responses with characteristics of healthy pulp tissue. However, tooth 22 had a negative response [26].

Panoramic and periapical radiographic examination revealed a radiolucent circumscribed lesion around the periapical region of tooth \#22 presenting features of periapical periodontitis. As well, unsatisfactory endodontic treatment of the same tooth was founded with signs of root perforation due to a previous treatment (Figure 1). The cone beam computed tomography (CBCT) scan was indicated to obtain an accurate diagnosis of the lesion and its relationship with the adjacent teeth and to confirm the presence of the root canal perforation (Figure 2).
The final diagnosis was symptomatic periapical periodontitis, and the treatment plan was to retreat the root canal and posteriorly to perform an endodontic surgery (apicoectomy), disinfect the periapical region by antimicrobial photodynamic therapy (aPDT), and seal the perforation area with bioceramic cement to prevent recontamination of the canal.

2.2. Therapeutic Interventions. Firstly, the root canal of tooth \#22 was retreated to disinfect the contaminated system because of the perforation. The canal was instrumented with the RECIPROC system R40/0.06 file (VDW, Munich, Germany) and irrigated by sodium hypochlorite $2.5 \%$ (Biodinâmica, Ibiporã, PR, Brazil) and ethylenediaminetetraacetic acid with detergent (EDTA-T) (Fórmula e Ação, São Paulo, SP, Brazil). The canal was then washed with $10 \mathrm{~mL}$ of sterile saline solution to be neutralized of any chemical substance and dried with paper points \#40.

The aPDT was then performed by filling the canal with methylene blue 0.005\% (Vetec Quimica Fina Ltda, Rio de Janeiro, RJ, Brazil) and maintained in the canal for $5 \mathrm{~min}$ as a preirradiation time. The irradiation procedure was performed using a low-power diode laser (MMOptics Ltda, São Carlos, Brazil) and an optical fiber $(0.40 \mathrm{~mm}$ diameter and $16 \pm 0.5 \mathrm{~mm}$ active surface length) placed into the canal. The irradiation was performed by a visible red wavelength of $660 \mathrm{~nm}$ and an output power of $100 \mathrm{~mW} / \mathrm{cm}^{2}$ activated for 2 min without interval, using a helical movement from apical to cervical direction. An energy density of approximately $120.0 \mathrm{~J} / \mathrm{cm}^{2}$ was applied [27].

The root canal was obturated in the same session with gutta-percha and Ah Plus sealer (Dentsply, DeTrey GmbH, Konstanz, Germany). No medication was prescribed before or during the treatment. The patient was advised to take acetaminophen (500 mg, maximum four times a day) in case of pain.

One week later, after tomographic planning, the apicoectomy surgery was performed under local anesthesia 


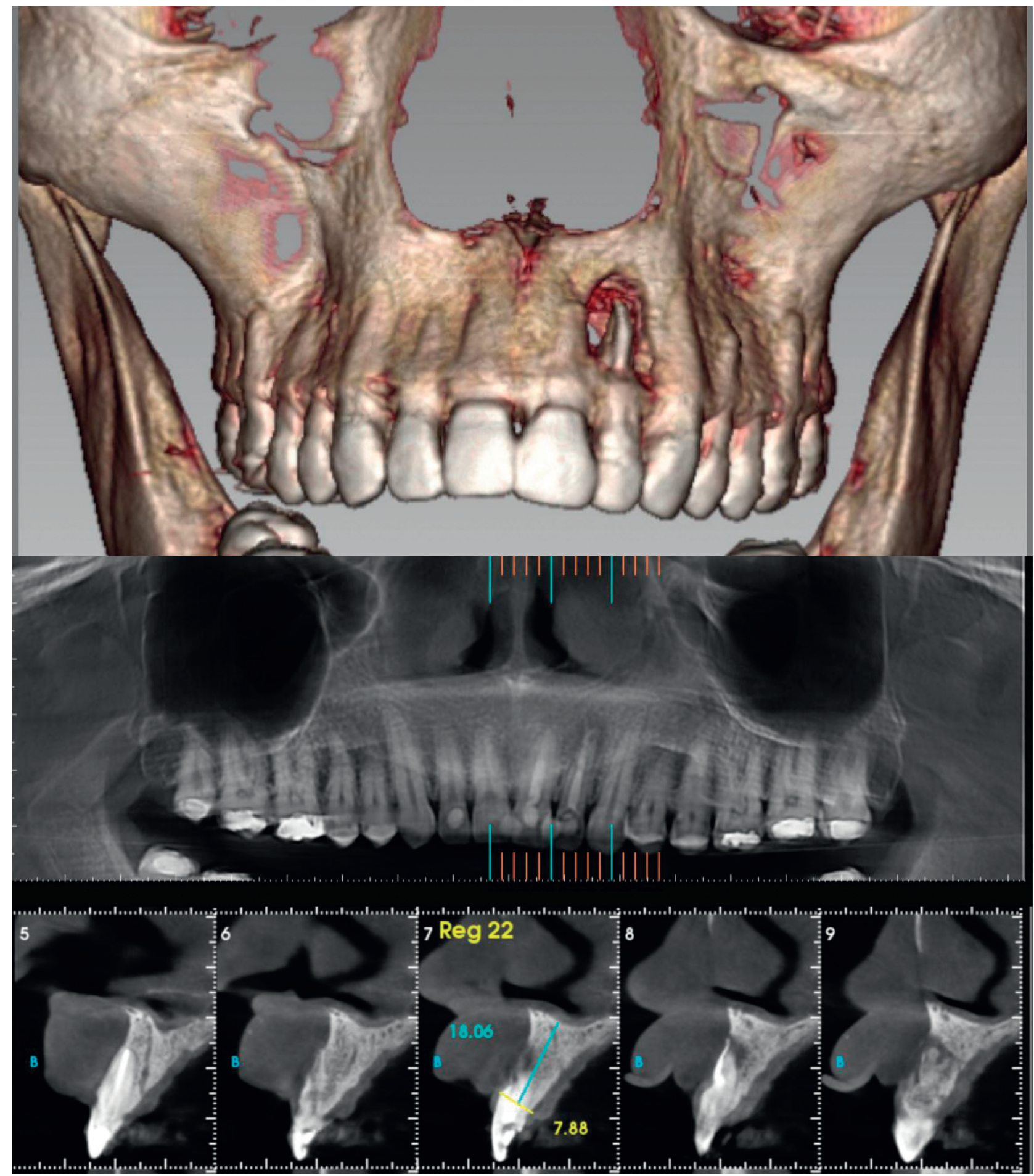

FIgURE 2: Initial CBCT images of the periapical lesion of tooth \#22.

using one anesthetic tube ( $4 \%$ articaine with epinephrine 1 : $100,000)$, with intraoral access to the lesion achieved via intrasulcular incision of the buccal region from teeth 11 to 24. After detachment of the flap, the perforation was clear and a minimum osteotomy was performed to obtain a surgery window using a surgical carbide drill no. 06 (Angelus Prima Dental Ltda., Londrina, PR, Brazil) under intense irrigation with sterile saline solution.
The apical third of the root was sectioned using Zekrya Surgical Bur (Dentsply, DeTrey GmbH, Konstanz, Germany) under intense irrigation with sterile saline solution, and then, the root canal was retroinstrumented by ultrasonic diamond tip P1 (Helse Ultrasonic, Santa Rosa de Viterbo, SP, Brazil) using CVDentus 100 ultrasound activator (CVDentus, São José dos Campos, Brazil). The surgery site was filled with methylene blue $0.005 \%$ and irradiated with a 


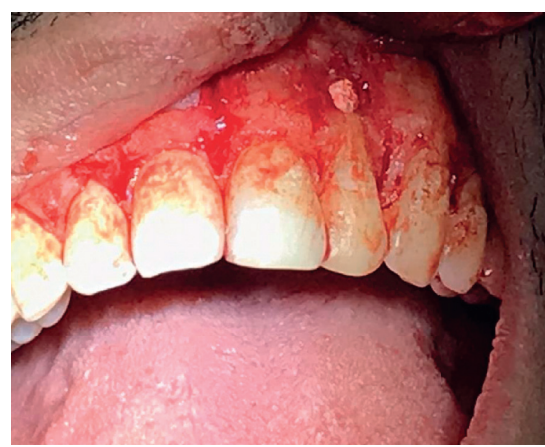

(a)

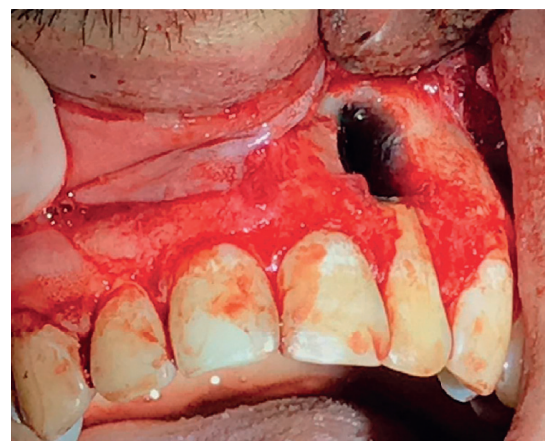

(d)

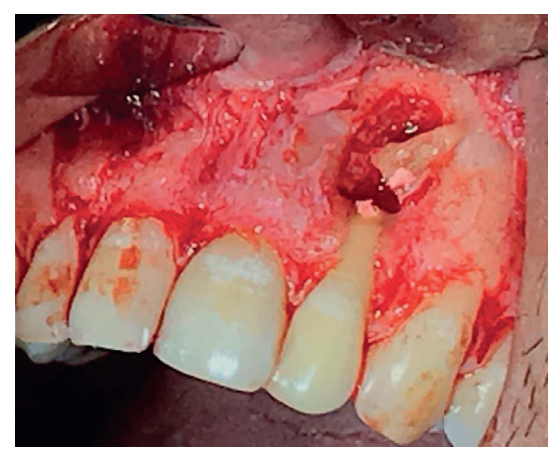

(b)

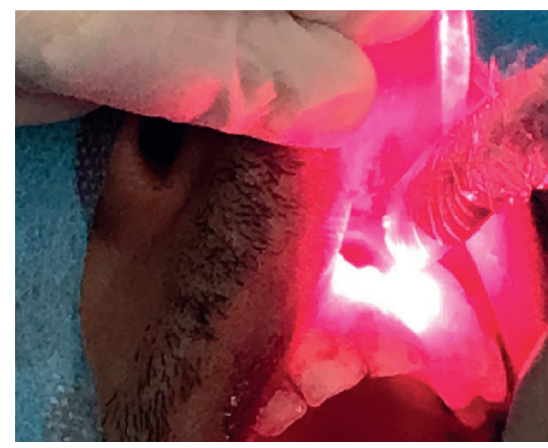

(e)

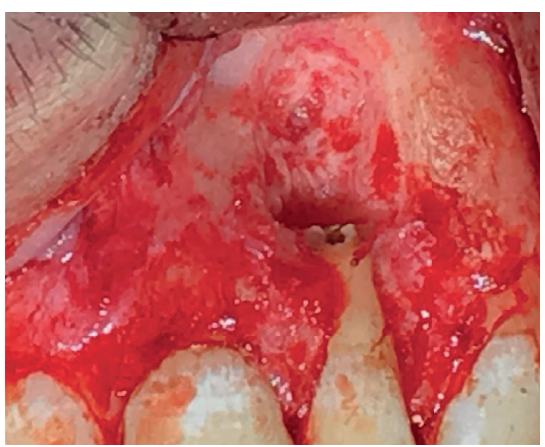

(c)

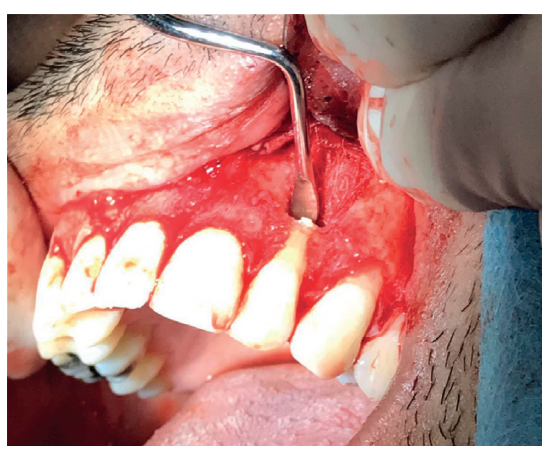

(f)

Figure 3: The surgical intervention. (a) Surgical window; (b) apicoectomy; (c) after retroinstrumentation; (d) methylene blue application; (e) laser irradiation; (f) retrofilling with $5 \mathrm{MO}$ cement.

low-power diode laser following the same protocol described above to obtain further decontamination. Then, the root canal was retrofilled with $5 \mathrm{MO}$ bioceramic cement (SHAM Dentico, Oman) manipulated following the manufacturer's guidelines (Figure 3). Finally, a bone graft and membrane were placed over the surgery window (Figure 4 ) to accelerate the periapical lesion bone regeneration [28], and the flap was repositioned, followed by intrasulcular suturing with 3-0 silk thread (Procare Xuyi Webest Medical Products Co, Jiangsu, China). Postoperative periapical radiography was performed immediately after suturing (Figure 5). The suture was removed ten days later, and the patient progressed well postoperatively without intercurrences.

2.3. Follow-Up and Outcomes. Ten days later, the patient had no postoperative intercurrences and an intraoral evaluation was performed to investigate any hematoma or edema. The patient related a slight edema in the first two days following the surgery that disappeared posteriorly. No exudate was observed or related.

Two follow-up sessions were performed after 30 days and 12 months. In these sessions, clinical intraoral examination was performed in addition to radiographic examination. In the second session (12 months later), the patient progression was evaluated by $\mathrm{CBCT}$ images and a bone neoformation was observed at the periapical area of tooth \#22 (Figure 6).

\section{Discussion}

The diagnosis of such cases has a direct effect on the treatment plan and outcome. In this case, the CBCT scan was indicated as it provides a three-dimensional mapping of the lesion and its relationship with the adjacent teeth and anatomical structure [29]. The periapical and panoramic radiography is less accurate, and the apicoectomy may not be performed based on their data [30].

The treatment plan was to retreat the infected tooth and associate this retreatment with surgical intervention, as the conventional endodontic retreatment alone is effective in limited cases, and this depends mainly on perforation type, its location, and the professional ability to approach it for repair [31]. However, surgical intervention has a good prognosis when followed by apical sealing with root-end fillings [32].

In this case report, $5 \mathrm{MO}$ cement was used as it presented a reparative feature and provided sealing of surgical areas [16]. However, not only $5 \mathrm{MO}$ but also many bioceramic cements principally mineral trioxide aggregate (MTA) and Biodentine have the same features $[19,33]$. MTA was indicated many years ago as an effective root-end filling material due to its biocompatibility and sealing ability [18], and since then, many bioceramic cements with the same intention presented similar results [22,34]. As well, modified MTA forms were indicated for high stress-bearing areas and especially for surgical sites [35]. 


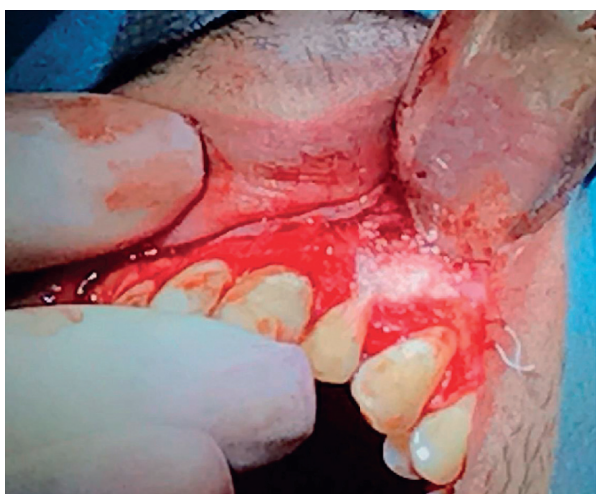

(a)

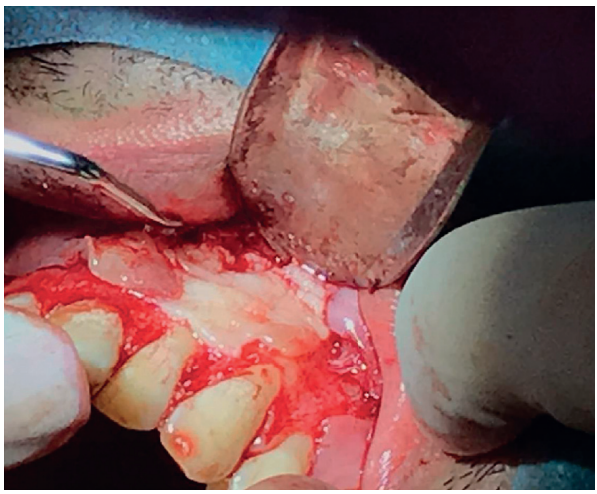

(b)

Figure 4: The surgical intervention. (a) Bone graft positioning and (b) membrane placement.

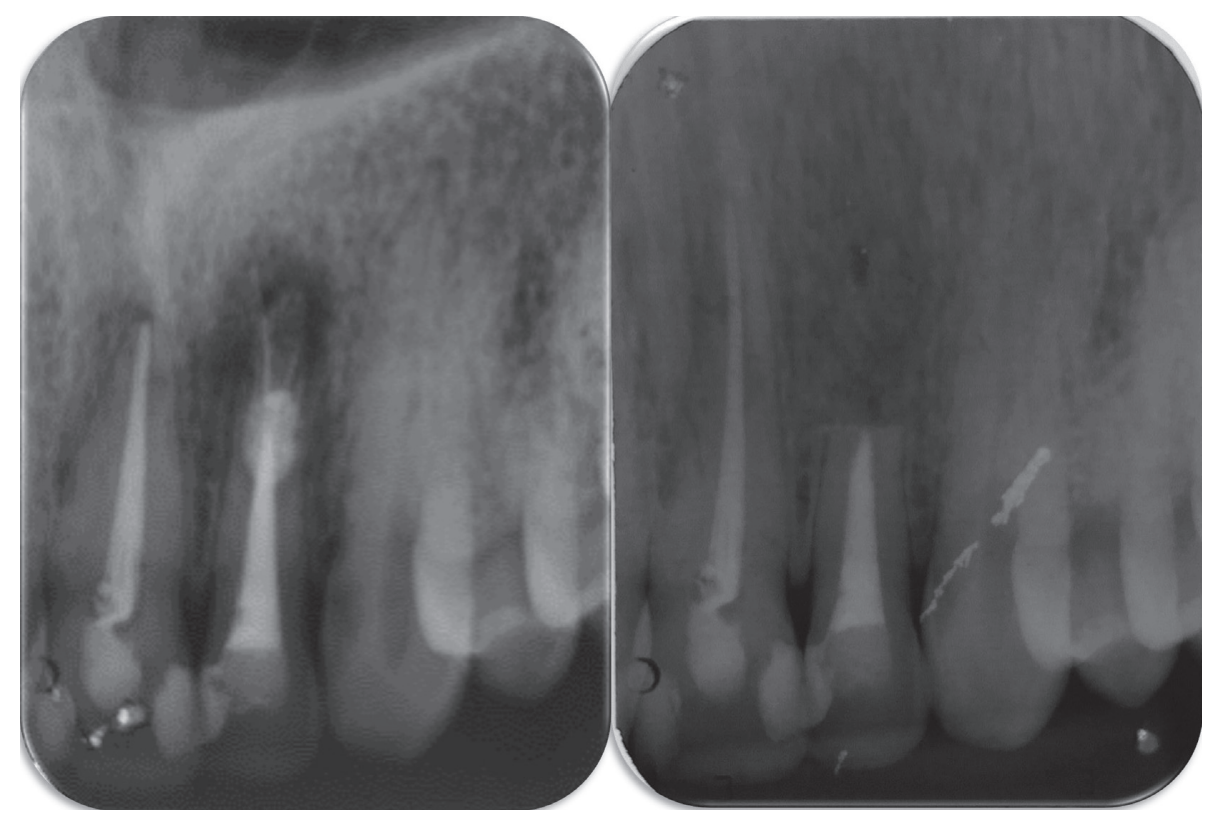

FIGURE 5: Postoperative periapical radiography immediately after suturing, compared with the initial one.

Another point to emphasize is the marginal adaptation of the retrofilling materials. Amalgam as an example was criticized and not indicated due to its expansion over time regardless of its thickness [36]; conversely, MTA has better adaption compared to amalgam and other materials [37]; even more, an improved stability of marginal adaptation of bioceramics over time was proved in a more recent study [38].

In the literature, bioceramic cements have low antimicrobial action; however, this ability to obtain reasonable results in terms of successful management of endodontic complications and accidents is related to the disinfection of the surgical site and root canal in the first place [39]. In this case report, the root canal was instrumented with the RECIPROC system [40] and irrigated with sodium hypochlorite which was proved as an effective antimicrobial agent over resistant microorganisms and its endotoxins $[3,8]$ and over the matrix metalloproteinases (MMPs) [41] responsible of extracellular matrix degradation and tissue destruction in apical periodontitis lesions [42, 43].

The apical third was retroinstrumented using the ultrasonic tip which is an effective method resulting in additional disinfection of the surgical site [44]. A diamond ultrasonic tip was used as it provokes a minimal number of postoperative cracks when compared to stainless steel tips [45].

Even more, aPDT was used both in root canal retreatment as it was indicated as an effective complementary technique over resistant microorganisms [6] and in the surgical site because it induces reparation of the lesion [5].

Lastly, the endodontic infection has a complex nature, as diverse microorganisms, endotoxins, MMPs, and 

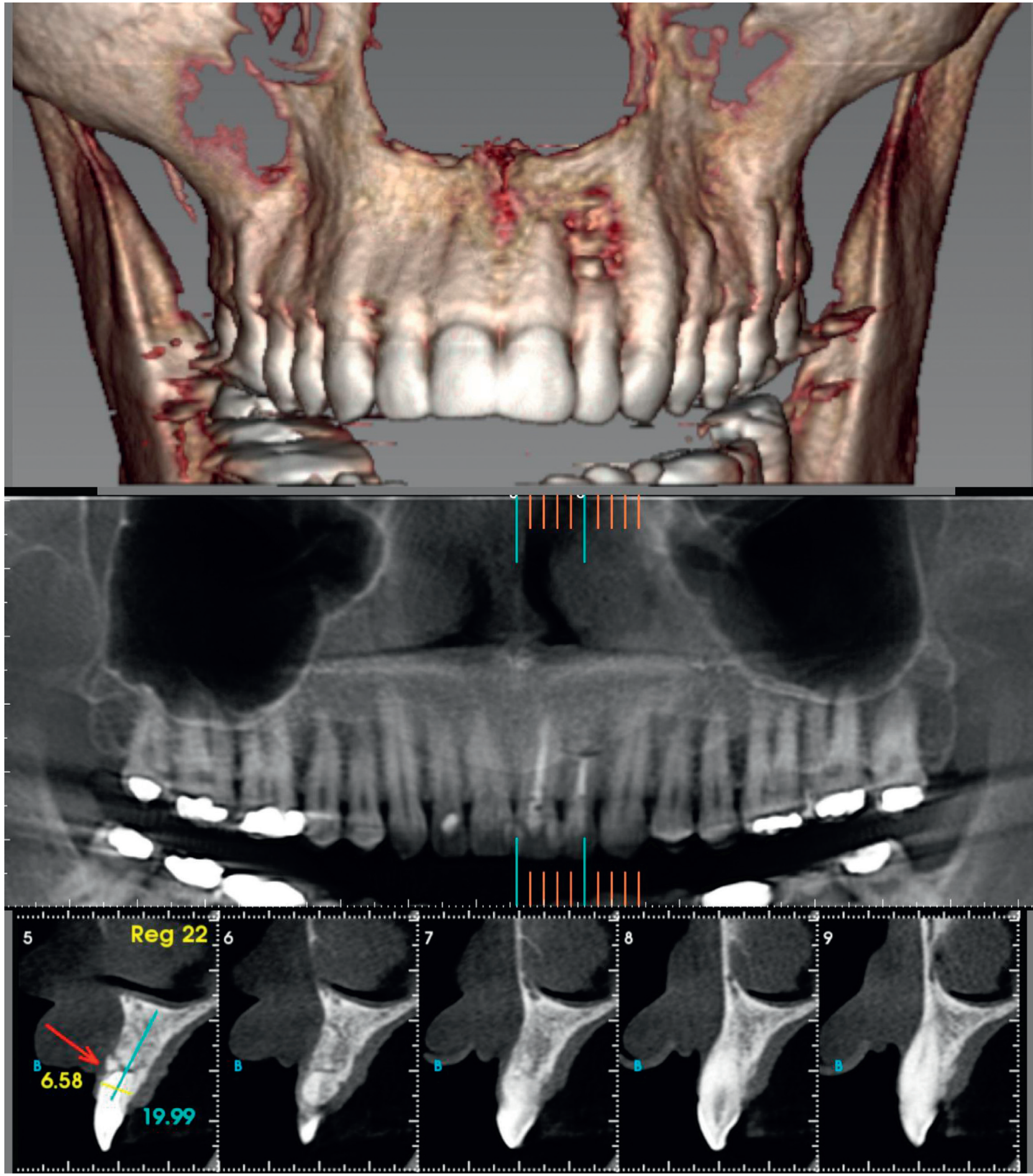

FIGURE 6: CBCT images of the periapical lesion of tooth \#22 after 12 months.

growth factors are involved [46]. Thus, the combined effect of the disinfection protocols of the endodontic retreatment using an effective instrumentation system, chemical agents, and complementary techniques in addition to the use of a good periapical sealer like bioceramic cements results in infection control of such cases.

\section{Conclusion}

$5 \mathrm{MO}$ bioceramic cement induces repair of periapical lesion, has the ability to seal the exposed periapical area of the tooth, and has a good marginal adaptation. The success obtained in this case depended mainly on root canal and surgical site disinfection by the photodynamic therapy. 


\section{Data Availability}

No data were used to support the findings of this study.

\section{Conflicts of Interest}

The authors declare that they have no conflicts of interest.

\section{Acknowledgments}

The authors wish to thank São Paulo State University for all their unconditional support in writing this case report.

\section{References}

[1] G. Korkhaus, "[Recent studies on the disinfection of the devitalized tooth]," SSO Schweiz Monatsschr Zahnheilkd, vol. 60, pp. 1134-1137, 1950.

[2] B. P. F. A. Gomes, M. E. Vianna, A. A. Zaia, J. F. A. Almeida, F. J. Souza-Filho, and C. C. R. Ferraz, "Chlorhexidine in endodontics," Brazilian Dental Journal, vol. 24, no. 2, pp. 89-102, 2013.

[3] A. S. Carvalho, L. D. D. Oliveira, F. G. D. Rosa Cardoso, and F. E. D. Oliveira, "Limewater and polymyxin B associated with $\mathrm{NaOCl}$ for endotoxin detoxification in root canal with necrotic pulp," Brazilian Dental Journal, vol. 27, no. 5, pp. 573-577, 2016.

[4] A. Abu Hasna, D. M. D. T. Ungaro, A. A. P. De Melo et al., "Nonsurgical endodontic management of dens invaginatus: a report of two cases," F1000Research, vol. 8, p. 2039, 2019.

[5] A. Abu Hasna, C. H. Ferrari, and C. A. Talge Carvalho, "Endodontic treatment of a large periapical cyst with the aid of antimicrobial photodynamic therapy-case report," Brazilian Dental Science, vol. 22, no. 4, pp. 561-568, 2019.

[6] A. Abu Hasna, R. D. Khoury, C. C. Toia et al., "In vitro evaluation of the antimicrobial effect of $\mathrm{N}$-acetylcysteine and photodynamic therapy on root canals infected with Enterococcus faecalis," Iranian Endodontic Journal, vol. 15, no. 4, pp. 236-245, 2020.

[7] E. I. F. Orozco, C. C. Toia, D. Cavalli et al., "Effect of passive ultrasonic activation on microorganisms in primary root canal infection: a randomized clinical trial," Journal of Applied Oral Science, vol. 28, Article ID e20190100, 2020.

[8] A. Abu Hasna, L. Pereira Da Silva, F. C. Pelegrini, C. L. R. Ferreira, L. D. De Oliveira, and C. A. T. Carvalho, "Effect of sodium hypochlorite solution and gel with/without passive ultrasonic irrigation on Enterococcus faecalis, Escherichia coli and their endotoxins," F1000Research, vol. 9, p. 642, 2020.

[9] A. Mazzoni, A. Pacifici, A. Zanza et al., "Assessment of realtime operative torque during nickel-titanium instrumentation with different lubricants," Applied Sciences, vol. 10, no. 18, p. $6201,2020$.

[10] M. R. Leonardo and R. D. T. Leonardo, Tratamento de Canais Radiculares, Editorial Medica Panamericana, Madrid, Spain, 2nd edition, 2017.

[11] C. Estrela, D. D. A. Decurcio, G. Rossi-Fedele, J. A. Silva, O. A. Guedes, and Á. H. Borges, "Root perforations: a review of diagnosis, prognosis and materials," Brazilian Oral Research, vol. 32, no. suppl 1, p. e73, 2018.

[12] M. K. AlRahabi, "Evaluation of complications of root canal treatment performed by undergraduate dental students," Libyan Journal of Medicine, vol. 12, no. 1, Article ID 1345582, 2017.
[13] J. Mente, N. Hage, T. Pfefferle et al., "Treatment outcome of mineral trioxide aggregate: repair of root perforations," Journal of Endodontics, vol. 36, no. 2, pp. 208-213, 2010.

[14] T. R. Ford, M. Torabinejad, D. J. McKendry, C. U. Hong, and S. P. Kariyawasam, "Use of mineral trioxide aggregate for repair of furcal perforations," Oral Surgery, Oral Medicine, Oral Pathology, Oral Radiology, and Endodontics, vol. 79, no. 6, pp. 756-763, 1995.

[15] A. Lopez Begazo, "[Paraendodontic surgery]," Odontología (Habana), vol. 15, pp. 72-80, 1967.

[16] E. I. Flores Orozco, A. Abu Hasna, M. Teotonio de Santos Junior et al., "Case report: interdisciplinary management of a complex odontoma with a periapical involvement of superior anterior teeth," F1000Research, vol. 8, p. 1531, 2019.

[17] A. Chércoles-Ruiz, A. Sánchez-Torres, and C. Gay-Escoda, "Endodontics, endodontic retreatment, and apical surgery versus tooth extraction and implant placement: a systematic review," Journal of Endodontics, vol. 43, no. 5, pp. 679-686, 2017.

[18] M. Torabinejad, T. F. Watson, and T. R. Pitt Ford, "Sealing ability of a mineral trioxide aggregate when used as a root end filling material," Journal of Endodontics, vol. 19, no. 12, pp. 591-595, 1993.

[19] S.-J. Lee, M. Monsef, and M. Torabinejad, "Sealing ability of a mineral trioxide aggregate for repair of lateral root perforations," Journal of Endodontics, vol. 19, no. 11, pp. 541-544, 1993.

[20] E. Apaydin, S. Shabahang, and M. Torabinejad, "Hard-tissue healing after application of fresh or set MTA as root-endfilling material," Journal of Endodontics, vol. 30, no. 1, pp. 21-24, 2004.

[21] G. Caron, J. Azérad, M.-O. Faure, P. Machtou, and Y. Boucher, "Use of a new retrograde filling material (Biodentine) for endodontic surgery: two case reports," International Journal of Oral Science, vol. 6, no. 4, pp. 250-253, 2014.

[22] M. N. A. Rachi, T. F. Al-Nahlawi, and M. T. Kouki, "New five minerals oxides pulp capping material compared with dycal," Dental Materials, vol. 30, p. e126, 2014.

[23] M. T. Lee, P. S. Bird, and L. J. Walsh, "Photo-activated disinfection of the root canal: a new role for lasers in endodontics," Australian Endodontic Journal, vol. 30, no. 3, pp. 93-98, 2004.

[24] E. Mester, T. Spiry, B. Szende, and J. G. Tota, "[Effect of laser radiation on the wound healing]," Zeitschrift für Experimentelle Chirurgie, vol. 4, pp. 307-312, 1971.

[25] B. Rathnakar, B. S. S. Rao, V. Prabhu, S. Chandra, and K. K. Mahato, "Laser-induced autofluorescence-based objective evaluation of burn tissue repair in mice," Lasers in Medical Science, vol. 33, no. 4, pp. 699-707, 2018.

[26] E. Chen and P. V. Abbott, "Dental pulp testing: a review," International Journal of Dentistry, vol. 2009, Article ID 365785, 12 pages, 2009.

[27] M. Schneider, G. Kirfel, M. Berthold, M. Frentzen, F. Krause, and A. Braun, "The impact of antimicrobial photodynamic therapy in an artificial biofilm model," Lasers in Medical Science, vol. 27, no. 3, pp. 615-620, 2012.

[28] P. Sreedevi, N. Varghese, and J. Varugheese, "Prognosis of periapical surgery using bonegrafts: a clinical study," Journal of Conservative Dentistry, vol. 14, no. 1, pp. 68-72, 2011.

[29] T. Venskutonis, G. Plotino, G. Juodzbalys, and L. Mickevičienè, "The importance of cone-beam computed tomography in the management of endodontic problems: a review of the literature," Journal of Endodontics, vol. 40, no. 12, pp. 1895-1901, 2014. 
[30] A. Ramis-Alario, B. Tarazona-Alvarez, J. Cervera-Ballester et al., "Comparison of diagnostic accuracy between periapical and panoramic radiographs and cone beam computed tomography in measuring the periapical area of teeth scheduled for periapical surgery. A cross-sectional study," Journal of Clinical and Experimental Dentistry, vol. 11, pp. e732-e738, 2019.

[31] F.-C. Li and W.-C. Hung, "Repair of a perforating internal resorption: two case reports," Journal of Dental Sciences, vol. 11, no. 3, pp. 338-342, 2016.

[32] M. Maddalone and M. Gagliani, "Periapical endodontic surgery: a 3-year follow-up study," International Endodontic Journal, vol. 36, no. 3, pp. 193-198, 2003.

[33] Ö. Malkondu, M. K. Kazandağ, and E. Kazazoğlu, "A review on biodentine, a contemporary dentine replacement and repair material," BioMed Research International, vol. 2014, Article ID 160951, 10 pages, 2014.

[34] N. Parinyaprom, A. Nirunsittirat, P. Chuveera et al., "Outcomes of direct pulp capping by using either ProRoot mineral trioxide aggregate or biodentine in permanent teeth with carious pulp exposure in 6- to 18-year-old patients: a randomized controlled trial," Journal of Endodontics, vol. 44, no. 3, pp. 341-348, 2018.

[35] A. Alqedairi, C. A. Muñoz-Viveros, E. A. Pantera et al., "Superfast set, strong and less degradable mineral trioxide aggregate cement," International Journal of Dentistry, vol. 2017, Article ID 3019136, 9 pages, 2017.

[36] M. M. Negm, "Microleakage associated with retrofilling of the apical two thirds with amalgam," Oral Surgery, Oral Medicine, Oral Pathology, vol. 70, no. 4, pp. 498-501, 1990.

[37] M. Torabinejad, P. W. Smith, J. D. Kettering, and T. R. Pitt Ford, "Comparative investigation of marginal adaptation of mineral trioxide aggregate and other commonly used rootend filling materials," Journal of Endodontics, vol. 21, no. 6, pp. 295-299, 1995.

[38] O. Donfrancesco, M. Seracchiani, A. Morese et al., "Analysis of stability in time of marginal adaptation of endosequence root repair material on biological samples," Dental Hypotheses, vol. 11, no. 1, pp. 11-15, 2020.

[39] A. P. Jardine, F. Montagner, R. M. Quintana, I. M. Zaccara, and P. M. P. Kopper, "Antimicrobial effect of bioceramic cements on multispecies microcosm biofilm: a confocal laser microscopy study," Clinical Oral Investigations, vol. 23, no. 3, pp. 1367-1372, 2019.

[40] D. Cavalli, C. C. Toia, E. I. Flores Orozco et al., "Effectiveness in the removal of endotoxins and microbiological profile in primary endodontic infections using 3 different instrumentation systems: a randomized clinical study," Journal of Endodontics, vol. 43, no. 8, pp. 1237-1245, 2017.

[41] C. A. T. Carvalho, A. Abu Hasna, A. S. Carvalho et al., "Clinical study of sodium hypochlorite, polymyxin B and limewater effect on MMP-3,-8,-9 in apical periodontitis," Brazilian Dental Journal, vol. 31, no. 2, pp. 116-121, 2020.

[42] J. F. Woessner and H. Nagase, Matrix Metalloproteinases and TIMPs-J. Frederick Woessner, Hideaki Nagase-Oxford University Press, Oxford, UK, 2019, https://global.oup.com/ academic/product/matrix-metalloproteinases-and-timps9780198502685 ? cc $=$ br\&lang $=$ en $\&$.

[43] T. Sorsa, L. Tjäderhane, and T. Salo, "Matrix metalloproteinases (MMPs) in oral diseases," Oral Diseases, vol. 10, no. 6, pp. 311-318, 2004.

[44] G. De Paolis, V. Vincenti, M. Prencipe, V. Milana, and G. Plotino, "Ultrasonics in endodontic surgery: a review of the literature,” Annali di Stomatologia, vol. 1, pp. 6-10, 2010.
[45] R. Rodríguez-Martos, D. Torres-Lagares, L. CastellanosCosano, M. Serrera-Figallo, J. Segura-Egea, and J. GutierrezPerez, "Evaluation of apical preparations performed with ultrasonic diamond and stainless steel tips at different intensities using a scanning electron microscope in endodontic surgery," Medicina Oral Patología Oral Y Cirugia Bucal, vol. 17, pp. e988-e993, 2012.

[46] B. P. F. D. A. Gomes and D. R. Herrera, "Etiologic role of root canal infection in apical periodontitis and its relationship with clinical symptomatology," Brazilian Oral Research, vol. 32, no. suppl 1, p. e69, 2018. 